\title{
Skin Reaction to Cetuximab as a Criterion for Treatment Selection in Head and Neck Cancer
}

\author{
PRIMOŽ STROJAN ${ }^{1,2}$, BRANKO ZAKOTNIK ${ }^{3}$, BARBARA ŽUMER ${ }^{1}$, KATARINA KARNER $^{1}$, \\ MARTA DREMELJ $^{1}$, BORIS JANČAR ${ }^{1}$, SIMONA JEREB ${ }^{4}$ and CVETKA GRAŠIČ-KUHAR ${ }^{3}$ \\ ${ }^{1}$ Department of Radiation Oncology, Institute of Oncology, Ljubljana, Slovenia; \\ ${ }^{2}$ Faculty of Medicine, University of Ljubljana, Ljubljana, Slovenia; \\ ${ }^{3}$ Department of Medical Oncology, Institute of Oncology, Ljubljana, Slovenia; \\ ${ }^{4}$ Department of Radiology, Institute of Oncology, Ljubljana, Slovenia
}

\begin{abstract}
Background/Aim: It can be hypothesized that in patients with locally advanced head and neck cancer and prominent cetuximab (CMb)-induced skin rash, immunoradiotherapy would result in a survival advantage over chemoradiotherapy with cisplatin $(C P)$. Patients and Methods: After a loading dose of $C M b$, one weekly cycle of $C M b$ and $C P$ concurrently with $R T$, patients who developed a grade $\geq 2$ rash proceeded with immunoradiotherapy, and those with a grade 0-1 rash had chemoradiotherapy. Results: A grade 3-4 allergic reaction to $C M b$ developed in 11/39 (28.2\%) patients and further recruitment was stopped. These patients proceeded treatment with CP. In early assessment of skin rash 10/28 patients qualified for chemoradiotherapy and 18/28 patients for immunoradiotherapy. There was no difference in survival between the two groups. Conclusion: Rate of serious $C M b$ induced hypersensitivity reactions was unacceptably high. Even though immunoradiotherapy was administered only to the prognostically most favorable group of patients, it resulted in no advantage over chemoradiotherapy.
\end{abstract}

In locally advanced squamous cell carcinoma of the head and neck (LASCCHN), the greatest overall survival (OS) benefit of combined treatment with radiotherapy (RT) and platinumbased chemotherapy versus RT alone was observed in concomitant use of both modalities. Recognized as the most effective were platinum-based mono-chemotherapy regimens where the hazard ratio (HR) of death was 0.74 (95\% confidence interval $[\mathrm{CI}]$ 0.67-0.82) (1). On the other hand, in patients with LASCCHN, a concomitant administration of

Correspondence to: Primož Strojan, Department of Radiation Oncology, Institute of Oncology, Ljubljana, Slovenia. Tel: +386 15879110, Fax: +386 15879400, e-mail: pstrojan@onko-i.si

Key Words: Head and neck cancer, skin rash, bioradiotherapy, chemoradiotherapy, treatment selection.
RT and cetuximab (CMb), an IgG1 monoclonal antibody with high affinity to the epidermal growth factor receptor, also resulted in a significant improvement of OS compared to RT alone (2). Furthermore, an update of the Bonner's pivotal study showed, for the patients treated with $\mathrm{CMb}$ and RT, that survival was significantly improved in those who experienced a prominent acneiform rash (grade 2-4) compared to the patients with no/mild rash (grade 0-1), giving the HR of death 0.49 (95\% CI=0.34-0.72) (3). Indeed, those patients with no/mild skin reaction to $\mathrm{CMb}$ had a median survival similar to the RT-alone group (25.6 vs. 29.3 months): obviously, they exerted no OS benefit and should, therefore, better have been treated with the combination of $\mathrm{RT}$ and $\mathrm{CP}$. The $\mathrm{CMb}$-induced rash developed within 15 days of the initiating treatment in three quarters of patents, with a prominent rash recorded in $61 \%$ of them (3).

On the basis of these findings a hypothesis was made that early assessment of a CMb-induced skin rash could be used for treatment stratification in patients with LASCCHN. Thus, it was anticipated that in patients who would develop a prominent skin rash after $\mathrm{CMb}$ administration, bioradiotherapy should be more effective than the combination of RT and mono-chemotherapy with cisplatin $(\mathrm{CP})$; whereas in those with no/mild rash induced by $\mathrm{CMb}$ administration, concomitant chemoradiotherapy with $\mathrm{CP}$ is expected to be more efficient than the RT-CMb combination. This study reports on the efficacy and toxicity results from the prospective study that tested the above hypothesis.

\section{Patients and Methods}

The trial was designed according to the Helsinki declaration and was approved by the National Medical Ethics Committee of the Republic of Slovenia (No. 149/06/11) and registered under the ClinicalTrials.gov with the following identifier: NCT01472653.

Patients. Patients with a newly diagnosed and histologically confirmed squamous cell carcinoma of the oral cavity, oropharynx, 
hypopharynx, or larynx, UICC TNM stage III-IVB, entered the study. Other eligibility criteria were age $\geq 18$ years; WHO performance status $0-2$; adequate hematologic, renal, and liver function; no history of previous malignancy in the last 5 years (except for non-melanoma skin cancer or in situ carcinoma of the uterine cervix); and an expected survival of more than 6 months. Patients with any medical condition precluding safe administration of the planned therapy, including allergy, were deemed ineligible. A written informed consent was obtained from all the patients.

The pre-treatment staging evaluation included a clinical examination, standard laboratory tests, an upper aerodigestive tract endoscopy, contrast-enhanced head and neck CT scan or MRI, chest radiography/CT, and an abdominal ultrasound/CT. Other tests were performed if clinically indicated (bone scan, PET-CT). Patients with $>5 \%$ weight loss were referred for gastrostomy feeding tube placement.

Study protocol (Figure 1). Induction chemotherapy was given only to patients with inoperable tumors and seriously impaired swallowing function that would soon necessitated a feeding-tube insertion. Criteria for technical inoperability were used as defined by Fu et al. (4). They received docetaxel $75 \mathrm{mg} / \mathrm{m}^{2}$ (day 2), CP 75 $\mathrm{mg} / \mathrm{m}^{2}$ (day 2), and 5 -fluorouracil $750 \mathrm{mg} / \mathrm{m}^{2} /$ day (continuous infusion, days 1-4), repeated every 21 days for 3 cycles. The dosing recommendations implemented in the case of toxicity were as described elsewhere (5).

One week before the first fraction of RT, all patients received a loading dose of $\mathrm{CMb}\left(400 \mathrm{mg} / \mathrm{m}^{2}\right.$, over $\left.120 \mathrm{~min}\right)$ and during the first week of RT, a combination of CMb $\left(250 \mathrm{mg} / \mathrm{m}^{2}\right)$ and CP $\left(30 \mathrm{mg} / \mathrm{m}^{2}\right)$ was concurrently administered via separate lines in 1 $\mathrm{h}$ infusions. Prior to $\mathrm{CMb}$ infusions, patients were pre-treated with the antihistamine clemastine $2 \mathrm{mg}$ and methylprednisolone $125 \mathrm{mg}$ IV. Magnesium and potassium were supplemented as indicated by the results of weekly biochemical analyses. If the creatinine clearance was reduced to $<60 \mathrm{ml} / \mathrm{min}$ and/or peripheral polyneuropathy grade $>1$ recorded, $\mathrm{CP}$ was replaced by carboplatin AUC 1.5 weekly.

Concomitant boost IMRT using $6 \mathrm{MV}$ photon beam and 35 fractions ( 1 fraction/day, 5 days/week) was delivered in all patients (6). The definition of clinical target volumes (CTV) took into consideration the natural barriers to tumor spread: the CTV70 included primary and nodal gross tumor volumes (GTV) and in CTV56 areas considered at risk for harboring microscopic disease were included. Areas around larger nodes and non-palpable but radiologically suspicious nodes in the neck (intermediate-risk volumes) were treated to $63 \mathrm{~Gy}$ (CTV63). The planning target volumes (PTVs) were created by adding a $5 \mathrm{~mm}$ isotropic margin around corresponding CTVs. The delineation of nodal levels followed the outlining guidelines. Delineated organs at risk (OAR) were the spinal cord, brainstem, parotid glands, and the mandible, whereas oral cavity, larynx, pharyngeal constrictor muscles, and the submandibular glands were marked as appropriate (7). Position verification was performed according to the eNAL protocol (8).

At the end of the first week of RT, assessment of skin rash was done according to the criteria of the National Cancer Institute CTCAE, version 3.0 (CTCAE v3.0). The patients with no/mild reaction (grade $\leq 1$ ) proceeded with concomitant chemoradiotherapy with $\mathrm{CP}\left(30 \mathrm{mg} / \mathrm{m}^{2} /\right.$ week, CP group), whereas the patients with a prominent skin rash (grade $\geq 2$ ) proceeded with bioradiotherapy with $\mathrm{CMb}\left(250 \mathrm{mg} / \mathrm{m}^{2} /\right.$ week, CMb group $)$.
Response evaluation and follow-up. During therapy, acute toxicity was evaluated weekly according to the CTCAE v3.0 criteria. After the end of treatment, patients were seen at 2-3 months intervals for the first two years end every 6 months thereafter, to record toxicity and tumor response. A radiological assessment of response was done after the completion of the induction chemotherapy (if any) and 1214 weeks post-concomitant therapy by using the RECIST 1.1 response criteria (9). Patients with residual tumor considered operable were referred for surgery. The scoring criteria of the European Organization for Research and Treatment of Cancer/Radiation Therapy Oncology Group were used for the evaluation of late treatment-related morbidity.

Detection of human papillomavirus DNA. To determine the association between human papillomavirus (HPV) and oropharyngeal tumors, extraction of DNA from primary tumor tissue sections and HPV E6/E7 mRNA transcripts detection were performed as described elsewhere (10).

Compliance with Ethical Standards. All procedures performed in studies involving human participants were in accordance with the ethical standards of the institutional and/or national research committee and with the 1964 Helsinki declaration and its later amendments or comparable ethical standards.

Statistical analysis. The primary objective of the study was radiological complete response rate at 12-14 weeks post-therapy, according to the RECIST 1.1 criteria (9). The secondary objectives were LRC (event: local and/or regional recurrence and death from any cause other than distant metastases), progression-free survival (PFS, event: any recurrence, new primary cancer, or death from any cause) and OS (event: death from any cause) at 2 years after therapy, acute and late toxicities. The survival times were calculated from the first day of therapy by using the Kaplan-Meier method, and the differences between the curves were tested by the log-rank test. For categorical variables, the chi-squared test or chi-squared test for trends were used. Statistical analyses were performed by the SPSS v16 software package and the differences at $p<0.05$ were considered statistically significant.

For study sample calculation, the HRs of death as calculated by Pignon et al. (for patients treated with platinum-based monochemotherapy vs. RT alone, 0.74) and by Bonner et al. (for patients treated with $\mathrm{CMb}$ and RT who experienced grade 2-4 vs. grade 0-1 acneiform rash, 0.49) were used $(1,3)$. Accordingly, the risk of death was reduced by an additional $25 \%$ in those who developed a prominent skin rash after $\mathrm{CMb}$ administration compared to patients treated with concomitant chemoradiotherapy with CP. Anticipating that variation of $25 \%$ between the two treatments reflects the difference in locoregional control (LRC) at 12-14 weeks posttherapy, and taking into account the $3 \%$ expected rate of grade $3 / 4$ allergic reactions to $\mathrm{CMb}$ and development of prominent rash in $60 \%$ of patients, a total of 120 patients would be included $(\alpha=0.05$, $\beta=0.8$ ): 50 of them allocated to $\mathrm{CP}$ group and 70 to the $\mathrm{CMb}$ group (11). The planned recruitment period was 3 years.

\section{Results}

Between December 2011 and July 2013, 39 patients entered the study. In this group, 11 allergic reactions of grade 3 (9 patients) and grade 4 (2 patients) were observed during the 


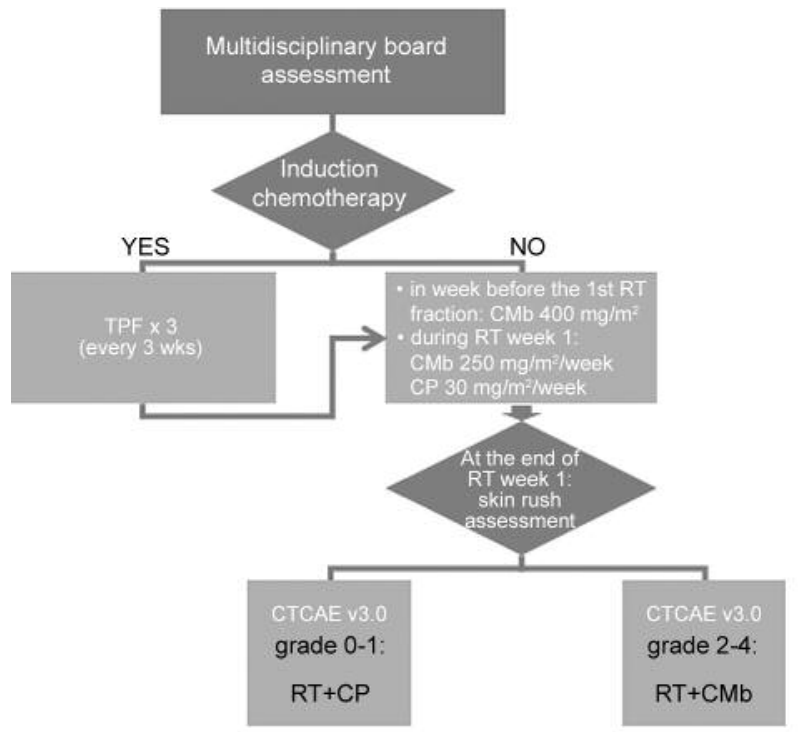

Figure 1. Treatment protocol. TPF: Docetaxel/cisplatin/5-fluorouracil. RT: radiotherapy; $C P$ : cisplatin; $C M b$ : cetuximab.

loading $\mathrm{CMb}$ infusion. This observation was reported to the National Medical Ethics Committee of the Republic of Slovenia which decided to prematurely stop the trial and further recruitment was terminated (No. 154/08/13).

There were 4 females and 35 males of a median age 57 years (range $=42-75$ years). The majority were active smokers $(30,76.9 \%)$, had an oropharyngeal primary tumor $(30,76.9 \%)$, and disease of UICC TNM stage IV $(35,89.7 \%)$ (Table I).

Compliance to treatment and response. Five (12.8\%) patients had induction chemotherapy and all received the planned doses of chemotherapeutics. After the third chemotherapy cycle, partial response locally and/or regionally was recorded radiologically in all of them. A full RT dose was delivered as per protocol in all 39 patients over 47-60 days (median, 51).

During application of CMb loading dose, a grade 3-4 allergic reaction developed in 11 patients $(28.2 \%)$ who proceeded with RT and the concomitant administration of CP (4-8 cycles, median 6). For assessment of CMb-induced skin rash at the end of the first week of RT, 28 patients were available. A grade 0-1 skin rash was recorded in 10 of these patients (35.7\%) who continued treatment with RT and CP (6-8 cycles, median 7). In further analyses, the patients who received RT and concomitant $\mathrm{CP}$, either due to an $\mathrm{CMb}$-induced allergic reaction or the absence of a prominent skin rash, were analyzed together (CP group, $\mathrm{N}=21$ ). Altogether, $\mathrm{CP}$ was replaced by weekly carboplatin due to renal toxicity in 6 patients $(28.6 \%)$ and all planned cycles of $\mathrm{CP} /$ carboplatin were administered in 10 patients
Table I. Patient and tumor characteristics.

\begin{tabular}{|c|c|c|c|c|}
\hline Characteristics & $\begin{array}{c}\text { All } \\
(\mathrm{N}=39)\end{array}$ & $\begin{array}{l}\mathrm{RT}+\mathrm{CP} \\
(\mathrm{N}=21)\end{array}$ & $\begin{array}{c}\mathrm{RT}+\mathrm{CMb} \\
(\mathrm{N}=18)\end{array}$ & $p$-Value ${ }^{3}$ \\
\hline \multicolumn{5}{|l|}{ Patients } \\
\hline Males & $34(87.2 \%)$ & $20(95.2 \%)$ & $14(77.8 \%)$ & n.s. \\
\hline $\operatorname{Age}^{1}$ & $57(42-75)$ & $57(42-75)$ & $58(45-63)$ & n.s. \\
\hline Active smokers & $30(76.9 \%)$ & $17(80.9 \%)$ & $13(72.2 \%)$ & n.s. \\
\hline \multicolumn{5}{|l|}{ Primary tumor site } \\
\hline Oral cavity & $2(5.1 \%)$ & $1(4.8 \%)$ & $1(5.6 \%)$ & n.s. \\
\hline Oropharynx & $30(76.9 \%)$ & $17(80.9 \%)$ & $13(72.2 \%)$ & \\
\hline Hypopharynx & $5(12.8 \%)$ & $2(9.5 \%)$ & $3(16.7 \%)$ & \\
\hline Larynx & $2(5.1 \%)$ & $1(4.8 \%)$ & $1(5.6 \%)$ & \\
\hline \multicolumn{5}{|l|}{ HPV status ${ }^{2}$} \\
\hline Positive & $8(26.7 \%)$ & $4(23.5 \%)$ & $4(30.8 \%)$ & n.s. \\
\hline Negative & $18(60 \%)$ & $10(58.8 \%)$ & $8(61.5 \%)$ & \\
\hline Unknown & $4(13.3 \%)$ & $3(17.6 \%)$ & $1(7.7 \%)$ & \\
\hline \multicolumn{5}{|l|}{ T-stage } \\
\hline $\mathrm{T} 1$ & $1(2.6 \%)$ & $1(4.8 \%)$ & 0 & n.s. \\
\hline $\mathrm{T} 2$ & $4(10.3 \%)$ & $1(4.8 \%)$ & $3(16.7 \%)$ & \\
\hline $\mathrm{T} 3$ & $13(33.3 \%)$ & $8(38.1 \%)$ & $5(27.8 \%)$ & \\
\hline $\mathrm{T} 4$ & $21(53.8 \%)$ & $11(52.4 \%)$ & $10(55.6 \%)$ & \\
\hline \multicolumn{5}{|l|}{$\mathrm{N}$-stage } \\
\hline No & $5(12.8 \%)$ & $1(4.8 \%)$ & $4(22.2 \%)$ & $0.034^{4}$ \\
\hline N1 & $4(10.3 \%)$ & 0 & $4(22.2 \%)$ & $0.072^{5}$ \\
\hline $\mathrm{N} 2 \mathrm{~A}$ & $2(5.1 \%)$ & $2(9.5 \%)$ & 0 & \\
\hline $\mathrm{N} 2 \mathrm{~B}$ & $12(30.8 \%)$ & $8(38.1 \%)$ & $4(22.2 \%)$ & \\
\hline $\mathrm{N} 2 \mathrm{C}$ & $10(25.6 \%)$ & $6(28.6 \%)$ & $4(22.2 \%)$ & \\
\hline N3 & $6(15.4 \%)$ & $4(19.0 \%)$ & $2(11.1 \%)$ & \\
\hline \multicolumn{5}{|l|}{ Overall UICC } \\
\hline \multicolumn{5}{|l|}{ TNM stage } \\
\hline Stage III & $3(7.7 \%)$ & 0 & $3(16.7 \%)$ & $0.059^{4}$ \\
\hline Stage IVA & $26(66.7 \%)$ & $14(66.7 \%)$ & $12(66.7 \%)$ & \\
\hline Stage IVB & $10(25.6 \%)$ & $7(33.3 \%)$ & $3(16.7 \%)$ & \\
\hline \multicolumn{5}{|c|}{ Induction chemotherapy } \\
\hline Yes & $5(12.8 \%)$ & $5(23.8 \%)$ & 0 & 0.027 \\
\hline No & $34(87.2 \%)$ & $16(76.2 \%)$ & $18(100.0 \%)$ & \\
\hline
\end{tabular}

${ }^{1}$ Median (range), in years; ${ }^{2}$ Oropharyngeal primary tumors, $\mathrm{N}=30$; ${ }^{3} \mathrm{RT}+\mathrm{CP} v s$. RT+CMb; ${ }^{4} \mathrm{Chi}$-square for trends; ${ }^{5} \mathrm{Chi}$-square test, stages N0-2A vs. N2B-3. N: Number of patients; RT: radiotherapy; CP: cisplatin; $\mathrm{CMb}$ : cetuximab; HPV: human papilloma virus; n.s.: not significant.

$(47.6 \%)$. Of the patients who received $\mathrm{CMb}$ and experienced no serious allergic reaction, 18 developed a skin rash of grade $\geq 2(\mathrm{CMb}$ group, $\mathrm{N}=18)$ and proceeded with RT and CMb (4-9 cycles, median 8; 16 patients received all planed cycles, $88.9 \%$ ).

After therapy, a complete response was achieved locoregionally in 14 patients $(66.7 \%, 95 \% \mathrm{CI}=52.1-81.3)$ from the $\mathrm{CP}$ group and 10 patients $(55.6 \%, 95 \% \mathrm{CI}=34.4-76.7)$ from the $\mathrm{CMb}$ group $(p>0.05)$. There were no statistically significant differences in the clinical characteristics between the two groups, except that more patients treated with $\mathrm{CP}$ had advanced nodal disease $(\mathrm{N} 2 \mathrm{~b}-3, p=0.07)$ and received induction chemotherapy $(p=0.05)$ (Table I). 
Survival. On the close out date on 31 December 2016, the median follow-up time of patients alive at the last follow-up examination was 3.9 years (range=3.6-5.0 years). Three patients from the $\mathrm{CMb}$ group had salvage surgery at primary tumor site 6,8 and 14 months after treatment completion; all died due to a further local progression of the disease. Salvage neck dissection was successfully performed in 3 patients, all from the $\mathrm{CP}$ group, 5.5, 8, and 12 months posttherapy. During follow-up, distant metastases were diagnosed in 6 patients (CP group 5, CMb group 1) and secondary primary tumor in 5 patients ( $\mathrm{CP}$ group $4, \mathrm{CMb}$ group 1 ; lung 2 , larynx, prostate, testis). On the close-out date, 13 patients were alive ( 12 with no evidence of disease) and 26 patients died: 21 due to tumor progression and 5 due to other causes, unrelated to the treated malignant disease.

The actuarial survival rates at 2 years in patients from the $\mathrm{CP}$ group and the $\mathrm{CMb}$ group are shown in Table II. No statistically significant differences were found between the two groups in respect to any of the studied survival objectives (Figure 2). Also, when only 28 patients were considered, who were grouped in respect to the grade of $\mathrm{CMb}$-induced skin rash (excluding patients with a grade 3/4 allergic reaction to $\mathrm{CMb}$ ), no difference in outcome was observed (Table II).

Acute and late toxicity. No treatment-related death was recorded in our patients. Locoregional treatment induced grade $\geq 3$ acute toxic events in $85.7 \%$ patients from the CP group and in all patients from the $\mathrm{CMb}$ group $(p>0.05)$ (Table III). During treatment, a nasogastric or a percutaneous endoscopic gastroscopy tube was inserted in 3 patients from each group $(p>0.05)$, and total parenteral nutrition was required in $10 \mathrm{CP}-$ group patients and in $5 \mathrm{CMb}$-group patients $(p>0.05)$ with a median duration of 11.5 days (range $=5-46$ days) and 11 days (range $=8-32$ days) $(p>0.05)$, respectively. The median change in weight from baseline ranged from $-16.8 \%$ to $0 \%$ (median, $-10.1 \%$ ) in the CP group and from $-18.3 \%$ to $+6.7 \%$ (median, $-9.1 \%)$ in the CMb group $(p>0.05)$. Significantly higher proportion of grade 3 radiomucositis $(p=0.05)$ and in field radiodermatitis $(p<0.01)$ developed when RT was combined with $\mathrm{CMb}$ (Table III).

Late toxicity was assessed in 16 patients who survived more than 6 months after treatment completion and had no residual or recurrent disease above the clavicles (median observation time 3.7 years, range $=1.3-4.9$ years). No grade 3 or higher late therapy-related toxicity was seen in these patients. Altogether, 15 adverse events of grade 2 were recorded in 6 patients $(66.7 \%)$ from CP the group, whereas in the $\mathrm{CMb}$ group 6 adverse events occurred in 3 patients $(42.9 \%)(p>0.05)$. None of the patients remained dependent on tube feeding at 3 months post-therapy and there was no difference in the occurrence of any grade 2 late toxicity between the two study groups (Table IV).
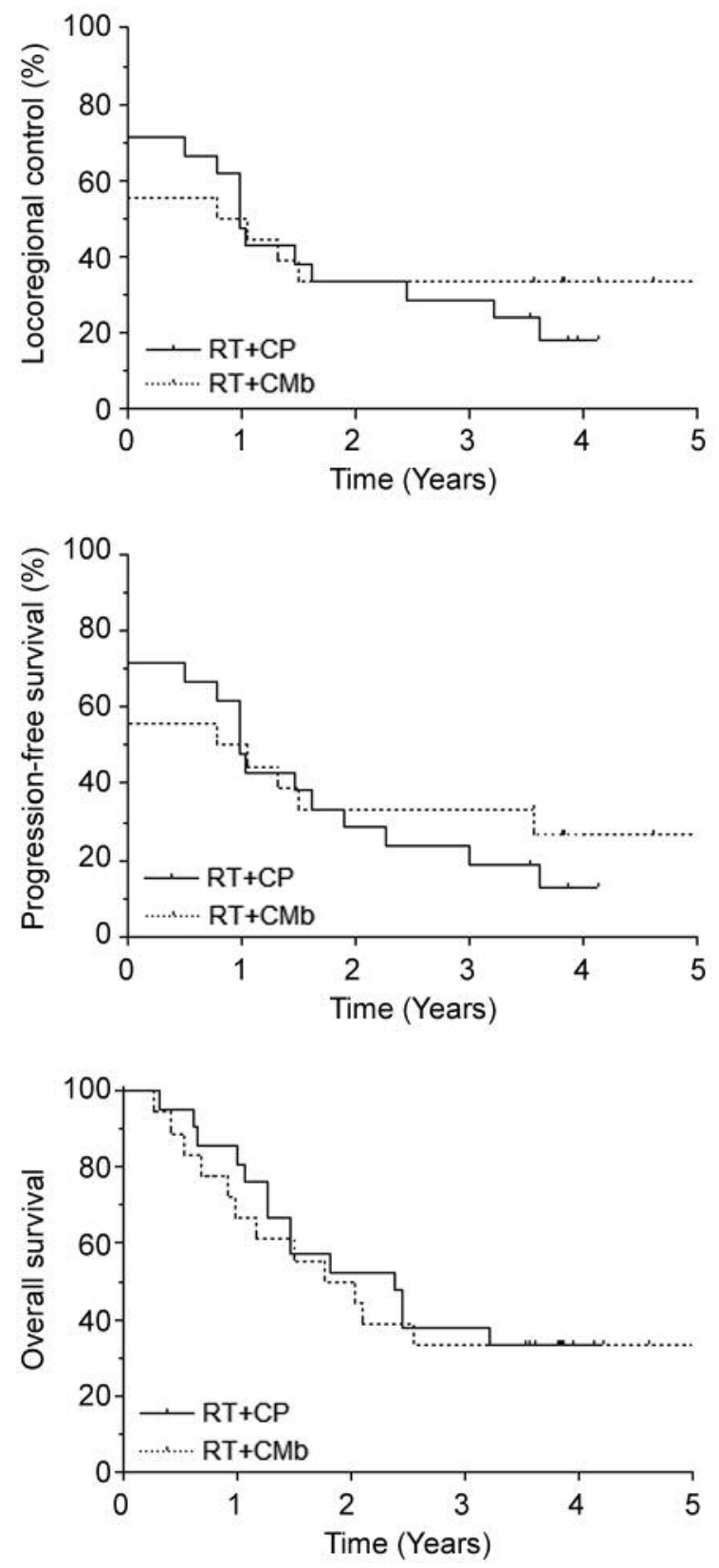

Figure 2. Survival of patients according to treatment group. RT: Radiotherapy; CP: cisplatin; CMb: cetuximab.

\section{Discussion}

In the present study, an early assessment of $\mathrm{CMb}$ inducedskin rash in patients with LASCCHN was used to select between the treatments with RT and concomitant weekly CP or $\mathrm{CMb}$. Due to the high rate $(28.2 \%)$ of grade $3 / 4$ allergic reactions to $\mathrm{CMb}$, the study was prematurely terminated, and the planned number of patients was not reached. Even in the 
Table II. Therapy response and survival.

\begin{tabular}{|c|c|c|c|c|c|}
\hline \multirow[t]{2}{*}{ At 2 years } & \multicolumn{2}{|c|}{$\mathrm{RT}+\mathrm{CP}$} & \multicolumn{2}{|c|}{$\mathrm{RT}+\mathrm{CMb}$} & \multirow[t]{2}{*}{$p$-Value } \\
\hline & $\%$ & $95 \% \mathrm{CI}$ & $\%$ & $95 \% \mathrm{CI}$ & \\
\hline \multicolumn{6}{|l|}{ All patients $(\mathrm{N}=39)$} \\
\hline Locoregional survival & 33.3 & $13.2-53.5$ & 33.3 & $11.6-55.1$ & n.s. \\
\hline Progression-free survival & 28.6 & $9.2-47.9$ & 33.3 & $11.6-55.1$ & n.s. \\
\hline Overall survival & 52.4 & $31.0-73.7$ & 50.0 & $26.9-73.1$ & n.s. \\
\hline \multicolumn{6}{|c|}{ Patients with assessment of skih rush $(\mathrm{N}=28)$} \\
\hline Locoregional survival & 50.0 & $19.0-81.0$ & 33.3 & $11.6-55.1$ & n.s. \\
\hline Progression-free survival & 40.0 & $9.6-70.4$ & 33.3 & $11.6-55.1$ & n.s. \\
\hline Overall survival & 50.0 & $19.0-81.0$ & 50.0 & $26.9-73.1$ & n.s. \\
\hline
\end{tabular}

RT: Radiotherapy; CO: cisplatin, CMb: cetuximab; CI: confidence interval; N: number of patients; n.s.: not significant.

Table III. Acute toxicities.

\begin{tabular}{|c|c|c|c|c|c|c|c|c|}
\hline \multirow[t]{2}{*}{ Acute toxicity } & \multicolumn{4}{|c|}{$\mathrm{RT}+\mathrm{CP}(\mathrm{N}=21)$} & \multicolumn{4}{|c|}{$\mathrm{RT}+\mathrm{CMb}(\mathrm{N}=18)$} \\
\hline & Grade 3 & Grade 4 & Total $\%$ & $\%$ & Grade 3 & Grade 4 & Total $\%$ & $\%$ \\
\hline Neutropenia & 3 & 0 & 3 & 14.3 & 0 & 0 & 0 & 0 \\
\hline Thrombocytopenia & 1 & 0 & 1 & 4.8 & 0 & 0 & 0 & 0 \\
\hline Hypomagnesemia & 1 & 0 & 1 & 4.8 & 1 & 0 & 1 & 5.6 \\
\hline Creatinine & 1 & 0 & 1 & 4.8 & 0 & 0 & 0 & 0 \\
\hline Dysphagia & 12 & 0 & 12 & 57.1 & 13 & 0 & 13 & 72.2 \\
\hline Weight loss & 10 & 0 & 10 & 47.6 & 7 & 0 & 7 & 38.9 \\
\hline $\mathrm{CMb}$-induced rash ${ }^{1}$ & 0 & 0 & 0 & 0 & 7 & 0 & 7 & 38.9 \\
\hline Mucositis $^{1}$ & 11 & 0 & 11 & 52.4 & 15 & & 15 & 83.3 \\
\hline (Radio)dermatitis, in-field ${ }^{1}$ & 1 & 0 & 1 & 4.8 & 11 & 1 & 12 & 61.1 \\
\hline Any AE (no. of patients) & 18 & 0 & 18 & 85.7 & 18 & 1 & 18 & 100 \\
\hline
\end{tabular}

${ }^{1} p<0.05 . \mathrm{N}$ : Number of patients; AE: adverse event.

Table IV. Late toxicities.

\begin{tabular}{|c|c|c|c|c|c|c|c|c|}
\hline \multirow[t]{2}{*}{ Late toxicity } & \multicolumn{4}{|c|}{$\mathrm{RT}+\mathrm{CP}(\mathrm{N}=9)$} & \multicolumn{4}{|c|}{$\mathrm{RT}+\mathrm{CMb}(\mathrm{N}=7)$} \\
\hline & Grade 2 & Grade 3 & Total $\%$ & $\%$ & Grade 2 & Grade 3 & Total \% & $\%$ \\
\hline Xerostomia & 3 & 0 & 3 & 33.3 & 0 & 0 & 0 & 0 \\
\hline Dysphagia & 2 & 0 & 2 & 22.2 & 0 & 0 & 0 & 0 \\
\hline Alteration of taste & 1 & 0 & 1 & 11.1 & 0 & 0 & 0 & 0 \\
\hline Laryngeal edema & 0 & 0 & 0 & 0 & 0 & 0 & 0 & 0 \\
\hline Skin fibrosis & 4 & 0 & 4 & 44.4 & 2 & 0 & 2 & 28.6 \\
\hline Altered skin pigmentation & 1 & 0 & 1 & 11.1 & 1 & 0 & 1 & 14.3 \\
\hline Chronic neuropathy, sensory & 1 & 0 & 1 & 11.1 & 0 & 0 & 0 & 0 \\
\hline Soft tissue necrosis & 0 & 0 & 0 & 0 & 0 & 0 & 0 & 0 \\
\hline Thyroid dysfunction & 3 & 0 & 3 & 33.3 & 3 & 0 & 0 & 42.9 \\
\hline Mandibular osteonecrosis & 0 & 0 & 0 & 0 & 0 & 0 & 0 & 0 \\
\hline Any AE (no. of patients) & 6 & 0 & 6 & 66.7 & 3 & 0 & 3 & 42.9 \\
\hline
\end{tabular}

$\mathrm{N}$ : Number of patients; AE: adverse event. 
potentially prognostically most favorable group of patients who developed a prominent skin rush to $\mathrm{CMb}$ that qualified them to enter the bioradiotherapy arm of the study, the combination of RT and $\mathrm{CMb}$ did not result in a survival advantage over chemoradiotherapy with CP. It only aggravated acute mucosal and in-field skin toxicity.

According to reports of pivotal trials employing $\mathrm{CMb}$ in cancer patients, the rate of grade 3-4 infusion related reactions associated with the first $\mathrm{CMb}$ administration was $<5 \%(2,12-14)$. In this respect, a premedication with histamine $\mathrm{H} 1$-receptor antagonist and corticosteroids was recommended as it appears beneficial in decreasing the occurrence of these reactions (15). Despite the rigorous use of anti-allergy premedication in our patients, grade 3-4 hypersensitivity reactions were observed in $28.2 \%$ of cases which resulted in the premature termination of the study. Indeed, a similar experience was obtained in our previous study employing $\mathrm{CMb}$ and $\mathrm{CP}$ concomitantly with RT, after TPF induction chemotherapy, and it was also reported from the Southeastern United States, i.e. 12.4-24.6\% of severe hypersensititvity reactions $(5,16-20)$.

The background mechanism is a type I anaphylactic reaction mediated by pre-existing $\mathrm{IgE}$ antibodies that crossreact with galactose- $\alpha-1,3$-galactose, an oligosaccharide on the Fab portion of the $\mathrm{CMb}$ heavy chain (21). Exposure to the lonestar tick (Amblyomma americanum) of the ixodidae family, with its proven ability to induce the production of IgE antibodies, was suggested to mediate presensitization of individuals $(19,22)$. Slovenia is a region well known for ixodides (23). Male gender (20), current smokers (20), history of allergy $(16,19)$, and patients with head and neck cancer $(18,24)$ were found more likely to be associated with severe hypersensitivity reactions, whereas premedication with steroids may have a protective effect (19). However, a successful identification of patients at risk of severe $\mathrm{CMb}$ induced hypersensitivity reactions is only possible by detection of pre-treatment elevated $\mathrm{IgE}$ levels with a specific enzyme-linked immunosorbent assay or by quantification of drug-specific IgE on basophils (25-27). Testing of Slovenian head and neck cancer patients and control subjects for specific pre-existing $\operatorname{IgE}$ is in progress.

Concomitant bioradiotherapy with $\mathrm{CMb}$ was introduced in routine clinical practice a decade ago, even though the results of a head-to-head comparison to concomitant chemoradiotherapy employing $\mathrm{CP}$ in patients with LASCCHN became available only recently (28). After an enrollment of 70 patients (53.8\% of the planned number), the trial was discontinued due to slow accrual and, consequently the results are under-powered. However, they showed no difference in the efficacy outcomes and $\mathrm{CMb}$ concomitant to RT increased acute toxicity and lowered compliance. In a subgroup analysis limited to the patients with oropharyngeal and oral cavity tumors only, the outcome was superior in patients treated with $\mathrm{CP}$ (28). A similar conclusion favoring platinum-based concomitant chemoradiotherapy over the $\mathrm{CMb}$ and RT combination was made by Petrelli et al. in a meta-analysis of 15 published series (3 of them were prospective) with a total of 1,808 patients included (29).

In our study, $\mathrm{CMb}$ administration was limited only to the patients who developed a prominent skin rash after the initial doses of $\mathrm{CMb}$. These patients were expected to have a death risk reduction of $25 \%$ compared to those treated with concomitant combination of RT and CP mono-therapy $(1,3)$. Beside Bonner's pivotal trial, a significant association between the appearance of $\mathrm{CMb}$-induced skin a rash and survival in patients with LASCCHN was detected also by others and was reported for other cancer types, i.e. colorectal, pancreatic and non-small-cell lung cancer, but was not seen in patients with recurrent or metastatic SCCHN treated with a combination of $\mathrm{CMb}$ plus platinum-based chemotherapy (5, 12, 30-34). Furthermore, two thirds of the oropharyngeal primary tumors in our study were HPV negative: analyzing over 600 patients with LASCCHN from two randomized RTOG trials, Bar-Ad et al. found that a severe skin rash was associated with a favorable outcome only in p16 negative oropharyngeal tumors (but not in patients with p16 positive tumors) (31). However, regardless of such a favorable selection, no survival advantage was observed with $\mathrm{CMb}$ over $\mathrm{CP}$-mono-therapy when combined with RT, despite a trend of more advanced nodal disease in the latter group and the fact that all planned doses of $\mathrm{CP} /$ carboplatin were administered to only $47.6 \%$ of these patients vs. $88.9 \%$ in the $\mathrm{CMb}$ group. In addition, $\mathrm{CP}$ in weekly doses of $30 \mathrm{mg} / \mathrm{m}^{2}$ was used which adversely affected a cumulative CP dose and intensity of chemoradiation (35). Of note: the same survival outcome was found when the bioradiotherapy arm was compared with patients who experienced no/mild rash to $\mathrm{CMb}(\mathrm{N}=10)$ or with all patients who received $\mathrm{CP}$ (patients with severe allergic reaction to $\mathrm{CMb}$ included, $\mathrm{N}=21$ ).

As already reported, $\mathrm{CMb}$ adds significantly to the acute mucosal and in-field cutaneous toxicity compared to the CP plus RT combination $(28,36)$, although no difference in acute toxicities between the two regimens has also been described (37). The rates of these two adverse events in our $\mathrm{CMb}$ patients were in the higher range of those reported in other studies (38-40), but still the compliance to CMb treatment was high and all patients received a planned RT dose in the time frame not significantly different from the CP group. No other difference in acute or late adverse effects was observed between the two groups.

The above observations must be interpreted with caution. Because of an early termination of the study due to safety reasons, it has several weaknesses, above all the low patients' number and a relatively short observation time. The number of enrolled patients reached only one third of the planned one, thus the study was too underpowered to show any statistically 
significant difference in efficacy outcomes. The reason for high proportion of $\mathrm{CMb}$ hypersensitivity reactions that remained unanswered and rather inhomogeneous study population (i.e. in respect to disease subsites, HPV status and treatment) are additional limitations of the study.

To conclude, the concomitant administration of $\mathrm{CMb}$ with RT resulted in unexpectedly and unacceptably high rate of serious hypersensitivity reactions in our patients with LASCCHN, which necessitated a premature termination of the study. Even though a full course $\mathrm{CMb}$ treatment was limited only to the potentially, prognostically most favorable group of patients who developed a prominent skin rash early, their survival outcome did not differ from that of patients treated with concomitant $\mathrm{CP}$ and RT. As the acute toxicity profile favored $\mathrm{CP}$ over $\mathrm{CMb}$, a refinement of selection criteria for the use of $\mathrm{CMb}$ in combination with $\mathrm{RT}$ is needed.

\section{Conflicts of Interest}

The Authors declare that they have no conflict of interest.

\section{References}

1 Pignon JP, le Maître A, Maillard E and Bourhis J; MACH-NC Collaborative Group: Meta-analysis of chemotherapy in head and neck cancer (MACH-NC): an update on 93 randomised trials and 17,346 patients. Radiother Onco 192: 4-14, 2009.

2 Bonner JA, Harari PM, Giralt J, Azarnia N, Shin DM, Cohen RB, Jones CU, Sur R, Raben D, Jassem J, Ove R, Kies MS, Baselga J, Youssoufian H, Amellal N, Rowinsky EK and Ang KK: Radiotherapy plus cetuximab for squamous-cell carcinoma of the head and neck. N Engl J Med 354: 567-578, 2006.

3 Bonner JA, Harari PM, Giralt J, Cohen RB, Jones CU, Sur RK, Raben D, Baselga J, Spencer SA, Zhu J, Youssoufian H, Rowinsky EK and Ang KK: Radiotherapy plus cetuximab for locoregionally advanced head and neck cancer: 5-year survival data from a phase 3 randomized trial, and relation between cetuximab-induced rash and survival. Lancet Oncol 11: 21-28, 2010.

4 Fu KK, Phillips TL, Silverberg IJ, Jacobs C, Goffinet DR, Chun C, Friedman MA, Kohler M, McWhirter K and Carter SK: Combined radiotherapy and chemotherapy with bleomycin and methotrexate for advanced inoperable head and neck cancer: update of a Northern California Oncology Group randomized trial. J Clin Oncol 5: 1410-1418, 1987.

5 Strojan P, Kuhar CG, Zumer B, Kadivec M, Karner K, Fajdiga I, Jančar B, Gale N, Poljak M, Kocjan BJ and Zakotnik B: TPF induction chemotherapy and concomitant irradiation with cisplatin and cetuximab in unresectable squamous cell carcinoma of the head and neck. Head Neck 36: 1555-1561, 2014.

6 Dahlke S, Steinmann D, Christiansen H, Durisin M, Eckardt A, Wegener $G$, Bremer $M$ and Meyer A: Impact of time factors on outcome in patients with head and neck cancer treated with definitive radio(chemo)therapy. In Vivo 31: 949-955, 2017.

7 De Felice F, Galdieri A, Abate G, Bulzonetti N, Musio D and Tombolini V: Definitive intensity-modulated radiation therapy in elderly patients with locally advanced oropharyngeal cancer. In Vivo 31: 455-459, 2017.
8 de Boer HC and Heijmen BJ: eNAL: an extension of the NAL setup correction protocol for effective use of weekly follow-up measurements. Int J Radiat Oncol Biol Phys 67: 1586-1595, 2007.

9 Eisenhauer EA, Therasse P, Bogaerts J, Schwartz LH, Sargent D, Ford R, Dancey J, Arbuck S, Gwyther S, Mooney M, Rubinstein L, Shankar L, Dodd L, Kaplan R, Lacombe D and Verweij J: New response evaluation criteria in solid tumours: revised RECIST guidelines (version 1.1). Eur J Cancer 45: 228247, 2009.

10 Strojan P, Zadnik V, Šifrer R, Lanišnik B, Didanović V, Jereb S, Poljak M, Kocjan BJ and Gale N: Incidence trends in head and neck squamous cell carcinoma in Slovenia, 1983-2009: role of human papillomavirus infection. Eur Arch Otorhinolaryngol 272: 3805-3814, 2015.

11 A'Hern RP: Sample size tables for exact single-stage phase II designs: Statist Med 20: 859-866, 2001.

12 Vermorken JB, Mesia R, Rivera F, Remenar E, Kawecki A, Rottey S, Erfan J, Zabolotnyy D, Kienzer HR, Cupissol D, Peyrade F, Benasso M, Vynnychenko I, De Raucourt D, Bokemeyer C, Schueler A, Amellal N and Hitt R: Platinumbased chemotherapy plus cetuximab in head and neck cancer. $\mathrm{N}$ Engl J Med 359: 1116-1127, 2008.

13 Cunningham D, Humblet Y, Siena S, Khayat D, Bleiberg H, Santoro A, Bets D, Mueser M, Harstrick A, Verslype C, Chau I and Van Cutsem E: Cetuximab monotherapy and cetuximab plus irinotecan in irinotecan-refractory metastatic colorectal cancer. N Engl J Med 351: 337-345, 2004.

14 Pirker R, Pereira JR, Szczesna A, von Pawel J, Krzakowski M, Ramlau R, Vynnychenko I, Park K, Yu CT, Ganul V, Roh JK, Bajetta E, O'Byrne K, de Marinis F, Eberhardt W, Goddemeier T, Emig $M$ and Gatzemeier U; FLEX Study Team: Cetuximab plus chemotherapy in patients with advanced non-small-cell lung cancer (FLEX): an open-label randomised phase III trial. Lancet 373: 1525-1531, 2009.

15 Siena S, Glynne-Jones R, Adenis A, Thaler J, Preusser P, Aguilar EA, Aapro MS, Loos AH, Esser R and Wilke H: Reduced incidence of infusion-related reactions in metastatic colorectal cancer during treatment with cetuximab plus irinotecan with combined corticosteroid and antihistamine premedication. Cancer 116: 1827-1837, 2010.

16 O'Neil BH, Allen R, Spigel DR, Stinchcombe TE, Moore DT, Berlin JD and Goldberg RM: High incidence of cetuximabrelated infusion reactions in Tennessee and North Carolina and the association with atopic history. J Clin Oncol 25: 3644-3648, 2007.

17 George TJ, LaPlant KD, Walden EO, Davis AB, Riggs CE, Close JL, George SN and Lynch JW: Managing cetuximab hypersensitivity infusion reactions: incidence, risk factors, prevention, and retreatment. J Support Oncol 8: 72-77, 2010.

18 Hansen NL, Chandiramani DV, Morse MA, Wei D, Hedrick NE and Hansen RA: Incidence and predictors of cetuximab hypersensitivity reactions in a North Carolina academic medical center. J Oncol Pharm Pract 17: 125-130, 2011.

19 Keating K, Walko C, Stephenson B, O'Neil BH and Weiss J: Incidence of cetuximab-related infusion reactions in oncology patients treated at the University of North Carolina Cancer Hospital. J Oncol Pharm Pract 20: 409-416, 2014.

20 Hopps S, Medina P, Pant S, Webb R, Moorman M and Borders E: Cetuximab hypersensitivity reactions: incidence and risk factors. J Oncol Pharm Pract 19: 222-227, 2013. 
21 Chung CH, Mirakhur B, Chan E, Le QT, Berlin J, Morse M, Murphy BA, Satinover SM, Hosen J, Mauro D, Slebos RJ, Zhou Q, Gold D, Hatley T, Hicklin DJ and Platts-Mills TA: Cetuximabinduced anaphylaxis and IgE specific for galactosea-1,3-galactose. N Eng J Med 358: 1109-1117, 2008.

22 Commins SP, James HR, Kelly LA, Pochan SL, Workman LJ, Perzanowski MS, Kocan KM, Fahy JV, Nganga LW, Ronmark E, Cooper PJ, and Platts-Mills TA: The relevance of tick bites to the production of $\operatorname{IgE}$ antibodies to the mammalian oligosaccharide galactose-a-1,3-galactose. J Allergy Clin Immunol 127: 1286-1293, 2011.

23 European Centre for Disease Prevention and Control: Ixodes ricinus - current known distribution in Europe, April 2017. https://ecdc.europa.eu/en/publications-data/ixodes-ricinus-currentknown-distribution-europe-april-2017 (Accessed 4 April 2018).

24 Grandvuillemin A, Disson-Dautriche A, Miremont-Salamé G, Fourrier-Reglat A and Sgro C; Réseau des Centres Régionaux de Français: Cetuximab infusion reactions: French pharmacovigilance database analysis. J Oncol Pharm Pract 19: 130-137, 2013.

25 Weiss J, Grilley Olson J, Deal AM, Chera B, Weissler M, Murphy BA, Hayes DN and Gilbert J: Using the galactosealpha-1,3-galactose enzyme-linked immunosorbent assay to predict anaphylaxis in response to cetuximab. Cancer 122: 16971701, 2016.

26 Dupont B, Mariotte D, Dugué AE, Clarisse B, Grellard JM, Babin E, Chauffert B, Dakpé S, Moldovan C, Bouhier-Leporrier K, Reimund JM, Di Fiore F, Zanetta S, Mailliez A, Do P, Peytier A, Galais MP, Florescu C, Schott R, Le Mauff B and Gervais R: Utility of serum anti-cetuximab immunoglobulin E levels to identify patients at a high risk of severe hypersensitivity reaction to cetuximab. Br J Clin Pharmacol 83: 623-631, 2017.

27 Iwamoto T, Okamoto A, Ishinaga H, Shimizu K, Gayle AA, Arai $\mathrm{N}$, Takeuchi $\mathrm{K}$ and Okuda M: A novel approach to predict cetuximab-induced hypersensitivity reaction: detection of drugspecific IgE on basophils. Cancer Med 5: 1004-1012, 2016.

28 Magrini SM, Buglione M, Corvò R, Pirtoli L, Paiar F, Ponticelli P, Petrucci A, Bacigalupo A, Crociani M, Lastrucci L, Vecchio S, Bonomo P, Pasinetti N, Triggiani L, Cavagnini R, Costa L, Tonoli S, Maddalo $\mathrm{M}$ and Grisanti S: Cetuximab and radiotherapy versus cisplatin and radiotherapy for locally advanced head and neck cancer: a randomized phase II trial. J Clin Oncol 34: 427-435, 2016.

29 Petrelli F, Coinu A, Riboldi V, Borgonovo K, Ghilardi M, Cabiddu M, Lonati V, Sarti E and Barni S: Concomitant platinum-based chemotherapy or cetuximab with radiotherapy for locally advanced head and neck cancer: a systematic review and meta-analysis of published studies. Oral Oncol 50: 10411048, 2014.

30 Roman J, Dissaux G, Gouillou M, Gobel Y, Potard G, Leclere JC, Conan-Charlet V, Gujral D, Abgral R, Guibourg B, Pradier $\mathrm{O}$ and Schick U: Prolonged overall treatment time and lack of skin rash negatively impact overall survival in locally advanced head and neck cancer patients treated with radiotherapy and concomitant cetuximab. Target Oncol 12: 505-512, 2017.

31 Bar-Ad V, Zhang QE, Harari PM, Axelrod R, Rosenthal DI, Trotti A, Jones CU, Garden AS, Song G, Foote RL, Raben D, Shenouda G, Spencer SA, Harris J and Le QT: Correlation between the severity of cetuximab-induced skin rash and clinical outcome for head and neck cancer patients: the RTOG experience. Int J Radiat Oncol Biol Phys 95: 1346-1354, 2016.
32 Jonker DJ, O'Callaghan CJ, Karapetis CS, Zalcberg JR, Tu D, Au HJ, Berry SR, Krahn M, Price T, Simes RJ, Tebbutt NC, van Hazel G, Wierzbicki R, Langer C and Moore MJ: Cetuximab for the treatment of colorectal cancer. N Engl J Med 357: 20402048, 2007.

33 Xiong HQ, Rosenberg A, LoBuglio A, Schmidt W, Wolff RA, Deutsch J, Needle $M$ and Abbruzzese JL: Cetuximab, a monoclonal antibody targeting the epidermal growth factor receptor, in combination with gemcitabine for advanced pancreatic cancer: a multicenter phase II Trial. J Clin Oncol 22: 2610-2616, 2004.

34 Gatzemeier U, von Pawel J, Vynnychenko I, Zatloukal P, de Marinis F, Eberhardt WE, Paz-Ares L, Schumacher KM, Goddemeier T, O'Byrne KJ and Pirker R: First-cycle rash and survival in patients with advanced non-small-cell lung cancer receiving cetuximab in combination with first-line chemotherapy: a subgroup analysis of data from the FLEX phase 3 study. Lancet Oncol 12: 30-37, 2011.

35 Strojan P, Vermorken JB, Beitler JJ, Saba NF, Haigentz M Jr., Bossi P, Worden FP, Langendijk JA, Eisbruch A, Mendenhall WM, Lee AW, Harrison LB, Bradford CR, Smee R, Silver CE, Rinaldo A and Ferlito A: Cumulative cisplatin dose in concurrent chemoradiotherapy for head and neck cancer: A systematic review. Head Neck 38: E2151-2158, 2016.

36 Walsh L, Gillham C, Dunne M, Fraser I, Hollywood D, Armstrong $\mathrm{J}$ and Thirion P: Toxicity of cetuximab versus cisplatin concurrent with radiotherapy in locally advanced head and neck squamous cell cancer (LAHNSCC). Radiother Oncol 98: 38-41, 2011.

37 Huang J, Zhang J, Shi C, Liu L and Wei Y: Survival, recurrence and toxicity of HNSCC in comparison of a radiotherapy combination with cisplatin versus cetuximab: a meta-analysis. BMC Cancer 16: 689, 2016.

38 Rambeau A, Gervais R, De Raucourt D, Babin E, Dugué AE, Florescu C, Blanchard D and Gery B: Retrospective evaluation of concomitant cetuximab and radiotherapy tolerance for locoregional advanced head and neck squamous cell carcinoma treatment in patients unfit for platinum-based chemotherapy. Eur Arch Otorhinolaryngol 274: 2883-2889, 2017.

39 Pryor DI, Burmeister E, Burmeister BH, Poulsen MG and Porceddu SV: Distinct patterns of stomatitis with concurrent cetuximab and radiotherapy for head and neck squamous cell carcinoma. Oral Oncol 47: 984-987, 2011.

40 Bonomo P, Loi M, Desideri I, Olmetto E, Delli Paoli C, Terziani F, Greto D, Mangoni M, Scoccianti S, Simontacchi G, Francolini G, Meattini I, Caini S and Livi L: Incidence of skin toxicity in squamous cell carcinoma of the head and neck treated with radiotherapy and cetuximab: a systematic review. Crit Rev Oncol Hematol 120: 98-110, 2017. 